\title{
Occupational exposure to asbestos and risk of cholangiocarcinoma: a population-based case- control study in four Nordic countries
}

\author{
Andrea Farioli, ${ }^{1}$ Kurt Straif, ${ }^{2}$ Giovanni Brandi, ${ }^{3,4}$ Stefania Curti, ${ }^{1}$ Kristina Kjaerheim ${ }^{5}$ \\ Jan Ivar Martinsen, ${ }^{5}$ Pär Sparen, ${ }^{6}$ Laufey Tryggvadottir, ${ }^{7,8}$ Elisabete Weiderpass, ${ }_{1}^{5,6,9,10}$ \\ Guido Biasco, ${ }^{3,4}$ Francesco Saverio Violante, ${ }^{1}$ Stefano Mattioli, ${ }^{1}$ Eero Pukkala ${ }^{11,12}$
}

\begin{abstract}
- Additional material is published online only. To view please visit the journal online (http://dx.doi.org/10.1136/ oemed-2017-104603).
\end{abstract}

For numbered affiliations see end of article.

\section{Correspondence to} Dr Stefano Mattioli, Department of Medical and Surgical Sciences (DIMEC), University of Bologna, 40138 Bologna, Italy; s.mattioli@unibo.it

Received 18 June 2017 Revised 1 September 2017 Accepted 28 September 2017 Published Online First 13 November 2017
Check for updates

\section{To cite: Farioli $A$,}

Straif K, Brandi G, et al.

Occup Environ Med

2018:75:191-198.

\section{ABSTRACT}

Objectives To assess the association between occupational exposure to asbestos and the risk of cholangiocarcinoma (CC).

Methods We conducted a case-control study nested in the Nordic Occupational Cancer (NOCCA) cohort. We studied 1458 intrahepatic CC (ICC) and 3972 extrahepatic CC (ECC) cases occurring among subjects born in 1920 or later in Finland, Iceland, Norway and Sweden. Each case was individually matched by birth year, gender and country to five population controls. The cumulative exposure to asbestos (measured in fibres (f)/ $\mathrm{ml} \times$ years) was assessed by applying the NOCCA jobexposure matrix to data on occupations collected during national population censuses (conducted in 1960, 1970, 1980/81 and 1990). Odds ratios (OR) and 95\% Cl were estimated using conditional logistic regression models adjusted by printing industry work.

Results We observed an increasing risk of ICC with cumulative exposure to asbestos: never exposed, OR 1.0 (reference category); 0.1-4.9 f/mL $\times$ years, OR $1.1(95 \%$ $\mathrm{Cl} 0.9$ to 1.3$) ; 5.0-9.9 \mathrm{f} / \mathrm{mL} \times$ years, OR $1.3(95 \% \mathrm{Cl} 0.9$ to 2.1$) ; 10.0-14.9 \mathrm{f} / \mathrm{mL} \times$ years, OR $1.6(95 \% \mathrm{Cl} 1.0$ to $2.5) ; \geq 15.0 \mathrm{f} / \mathrm{mL} \times$ years, OR $1.7(95 \% \mathrm{Cl} 1.1$ to 2.6$)$. We did not observe an association between cumulative asbestos exposure and ECC.

Conclusions Our study provides evidence that exposure to asbestos might be a risk factor for ICC. Our findings also suggest that the association between ECC and asbestos is null or weaker than that observed for ICC. Further studies based on large industrial cohorts of asbestos workers and possibly accounting for personal characteristics and clinical history are needed.

\section{INTRODUCTION}

Cholangiocarcinomas (CC) are aggressive primary malignancies of the biliary tract characterised by a very poor prognosis. ${ }^{1}$ In clinical practice, CC is divided into intrahepatic (ICC) and extrahepatic (ECC); the latter also includes hilar CC. ${ }^{2}$ This anatomical classification also reflects the different origin of multipotent stem cells suspected to be involved in the genesis of ICC and ECC. ${ }^{3}$ Moreover, the available epidemiological evidence demonstrates that ICC and ECC have different epidemiological features (ie, incidence and aetiological factors). ${ }^{4}$ While the incidence of ECC has remained stable over the past decades, a marked increase in the

\section{What this paper adds?}

- The association between cholangiocarcinoma and occupational exposure to asbestos was hypothesised based on the findings from a small hospital-based case-control study.

- Our population-based case-control study conducted in four Nordic countries supports the hypothesis that occupational exposure to asbestos is a risk factor for intrahepatic cholangiocarcinoma (ICC), while no evidence was observed for extrahepatic cholangiocarcinoma (ECC).

- Further studies, such as pooled analyses of asbestos cohorts, are necessary to assess the strength of the association between asbestos and ICC and to clarify the observed differences between ICC and ECC.

incidence of ICC has been reported worldwide. ${ }^{5}$ In Western countries, the rise in the number of cases of ICC cannot be readily explained by well-established major risk factors, which include infectious diseases (hepatitis B and C viruses, Opisthorchis viverrini and Clonorchis sinsensis infestations), congenital/inherited conditions (bile duct cysts, Caroli's disease, haemochromatosis and Wilson's disease), liver inflammatory diseases (primary sclerosing cholangitis, cirrhosis, non-alcoholic fatty liver disease) and personal habits (heavy alcohol consumption, cigarette smoking and obesity)..$^{5-7}$ Thus, recent studies have focused on possible occupational and environmental determinants of ICC. In particular, several studies documented an increased incidence of ICC among workers in the printing industry, possibly due to exposure to inhaled volatile organic compounds such as 1,2-dichloropropane and dichloromethane. ${ }^{6-10}$ Also, CC has been associated with occupational asbestos exposure in a retrospective case-control study, where a fourfold increase in the risk of ICC was observed among ever exposed subjects compared with never exposed. ${ }^{11}$ To our best knowledge, this is the only study that has specifically investigated the role of asbestos in the genesis of CC, although several limitations were present, such as the crude exposure assessment (ever/never exposed), the use of an historical 
control group and the limited size of the study population (41 ICC and 59 ECC cases). ${ }^{11}$

We aimed to investigate further the association between occupational exposure to asbestos and the risk of ICC and ECC using data from a large population study conducted in the Nordic countries.

\section{MATERIALS AND METHODS \\ Study design and population}

We conducted a case-control study nested in the Nordic Occupational Cohort Study (NOCCA). ${ }^{12}$ The NOCCA cohort includes 15 million persons from Denmark, Finland, Iceland, Norway and Sweden who participated in at least one population census in $1960,1970,1980 / 81$ or 1990 . The present study, based on individual records, is restricted to four countries (Finland, Iceland, Norway and Sweden) as we had no access to individual data from Denmark.

The NOCCA cohort was conceived to study occupational risk factors of cancer. The detailed methods have been described elsewhere. ${ }^{12}$ Briefly, census data were linked to national population registries through personal identity codes in order to identify data on cancer, death and emigration. Data on occupation (classified based on national standard occupational codes) were available from all four censuses in Sweden, from 1960, 1970 and 1980 in Norway, and from 1970 and a later census in Finland. In Iceland an electronic database of census data was available only for 1981. All participants in the aforementioned censuses were followed up in the NOCCA cohort until death, emigration or the end of the study (2005 in Finland and Sweden, 2004 in Iceland, 2003 in Norway).

In the present study we considered all incident cases of CC reported to the cancer registries of Finland, Iceland, Norway and Sweden between the first available census and end of follow-up of the NOCCA study. Based on the site of occurrence, we distinguished ICC, ECC and not otherwise specified CC (site of occurrence non-identifiable). Table $\mathrm{A}$ in online supplementary file shows the International Classification of Diseases codes (versions 7,8 and 10 ) used in each of the four participating countries to identify CC. ${ }^{10}$

Each case was individually matched by gender, birth year and country to five population controls randomly sampled among those who were alive and had not been diagnosed with CC on the date of diagnosis of the case (hereafter the 'reference date').

As estimates on the potential exposure to asbestos were available only from 1945 (see section below) and major changes to the use of asbestos after World War II occurred in the Nordic countries, ${ }^{1314}$ we decided to restrict our study to those subjects who had spent the majority of their working life after 1945. We therefore excluded from the analyses all subjects born before 1920.

The NOCCA study has been approved by the ethical committees and the data inspection boards in each of the Nordic countries.

\section{Exposure assessment}

The exposure to asbestos for each subject was estimated by applying the NOCCA job-exposure matrix (JEM) to the available occupational codes. ${ }^{15}$ This JEM was created by national experts from the Nordic countries starting with the Finnish JEM ${ }^{16}$; it covers more than 300 specific occupations, 29 exposure agents and four periods: 1945-59, 1960-74, 1975-84 and 1985-94. Asbestos exposure was defined as the inhalation of any form of asbestos fibres (length $>5 \mu \mathrm{m}$, diameter $<3 \mu \mathrm{m}$ and aspect ratio of at least $3: 1$ ) or asbestos-containing material. The probability of exposure ( $\mathrm{P}$, the proportion of workers exposed to asbestos within each occupational code) and the mean level of exposure (L) measured in fibres (f)/ml among the exposed workers were estimated by occupational code, country and period. Only occupations where the probability of exposure was $>5 \%$ were classified as exposed to asbestos (ie, the exposure was classified as null if $\mathrm{P}$ was $<0.05) .{ }^{15}$

Even though at least one occupational code was available for all subjects in the research database, the national classification schemes include some uninformative categories (eg, unknown occupation, new workers seeking employment, workers reporting occupations unidentifiable or inadequately described). As occupational exposure to asbestos was relatively common in the general population during the study period, ${ }^{17}$ we were not confident in assuming a zero level of occupational exposure to asbestos for individuals with unclassified occupations and we decided to recode as missing information the occupational codes reported in table B of online supplementary file.

We applied four different metrics to assess the effect of asbestos exposure on the risk of CC. First, we divided the study population into never or ever exposed to asbestos. Second, we classified each subject based on the maximum level $(\mathrm{P} \times \mathrm{L})$ of exposure to asbestos during his/her working life (as assessed using the available occupational codes). Third, we studied the effect of the duration of exposure to asbestos. For this purpose, we assumed that the employment period of each subject started at the age of 20 and ended at the age of 65 . If a person showed different occupational codes in the census records, we assumed that the occupation had changed in the mid-point between two censuses. We defined the duration (D) of the exposure to asbestos as the total number of years spent by each individual in an occupation with a non-zero level of asbestos exposure. The last metric applied was the cumulative exposure calculated as $\mathrm{P} \times \mathrm{L} \times \mathrm{D}$ (measured in $\mathrm{f} / \mathrm{ml} \times$ year). For subjects with different occupations over the studied period, the cumulative exposure was calculated by summing up all their $\mathrm{P} \times \mathrm{L} \times \mathrm{D}$ values. Assuming that a solid cancer develops over a number of years, we conducted four sets of analyses where cumulative exposure was calculated with no lagging or assuming a 10-, 20- or 30-year lag period (ie, not considering the exposure occurred 10,20 or 30 years before the reference date).

As previous reports have suggested that the risk of CC might be increased among workers in the printing industry, ${ }^{10}$ we hypothesised that work in the printing industry might be a confounder of the studied association. Due to the limited number of printing industry workers in our study population, we only created a binary qualitative exposure variable (never/ever exposed) and we did not attempt to create a quantitative exposure variable. The occupational codes used to identify printing industry workers are reported in table $\mathrm{C}$ in online supplementary file. ${ }^{10}$

\section{Statistical analysis}

We first studied the effect of asbestos exposure on the risk of CC. We then conducted separate analyses for ICC and ECC because available evidence suggests that asbestos might be a risk factor particularly for ICC. ${ }^{11}$

The correlations between continuous variables were assessed using Spearman's rank correlation coefficient (Spearman rho). All quantitative exposure variables (maximum level, duration and cumulative exposure) were recoded into ordinal variables. We selected values corresponding to the 50th and 90th percentiles of the exposure variable distribution among all ever exposed 
subjects as cut-off points for categorisation; never exposed individuals were used as the reference group. To better assess the exposure-response between $\mathrm{CC}$ and cumulative exposure to asbestos (the main exposure metric), we created a further ordinal variable based on the observed distribution of the cumulative exposure to asbestos in our study population to identify equal intervals of exposure: never exposed $(0 \mathrm{f} / \mathrm{mL} \times$ years $) ; 0.1-4.9 \mathrm{f} /$ $\mathrm{mL} \times$ years; 5.0-9.9f/mL $\times$ years; $10.0-14.9 \mathrm{f} / \mathrm{mL} \times$ years; and $\geq 15.0 \mathrm{f} / \mathrm{mL} \times$ years.

We estimated odds ratios (ORs) and 95\% CIs of CC by fitting logistic regression models conditioned on matching variables (gender, birth year and country); we also conducted a set of analyses adjusted by work in the printing industry. Linear trends for ordinal exposure variables (ie, exposure categories ranked from the lowest to the highest) were evaluated using the Wald test, treating the variable as a continuous variable (introduced in the model with one degree of freedom). When studying cumulative exposure calculated assuming different lag periods, we performed a model comparison by means of the Bayesian information criterion (BIC) proposed by Schwarz. ${ }^{18}$ The BIC for a regression model is calculated based on the $\log$-likelihood $(\operatorname{lnL})$, the number of parameters estimated $(\mathrm{k})$ and the sample size $(\mathrm{N})$ according to the formula: BIC $=-2 * \ln \mathrm{L}+\mathrm{k} * \ln (\mathrm{N})$. The BIC allows the comparison of non-nested regression models; the lower the BIC, the better is the fit of the model to the observed data ${ }^{18}$. We conducted analyses stratified by gender, country and reference age to explore possible effect modifiers.

All analyses were performed using Stata 14.1 SE (Stata Corporation, College Station, Texas, USA). A two-sided p value $<0.05$ was defined as statistically significant.

\section{RESULTS}

This database from four Nordic countries includes 2645 subjects with ICC, 10753 with ECC and 7580 with not otherwise specified CC diagnosed between 1961 and 2005. After the exclusion of subjects born before 1920 and of those without occupational codes informative on their past exposure to asbestos, we included in our final analysis 1458 ICC, 3972 ECC and 2801 not otherwise specified CC (figure 1).

Table 1 presents the characteristics of the study population. Both ICC and ECC were more common among men than women (53.8\% of ICC and 55.1\% of ECC). As expected, most CC cases were aged 60 years or more. The majority of the cases were diagnosed in Sweden and Finland, while Iceland contributed only 73 diagnoses. A total of 503 subjects (1.1\% of the study population) were classified as ever employed in the printing industry. The overall prevalence of past exposure to asbestos was higher among controls $(17.0 \%)$ than cases $(16.6 \%)$; however, the prevalence increased to 19.7\% when considering ICC cases solely. Among workers ever

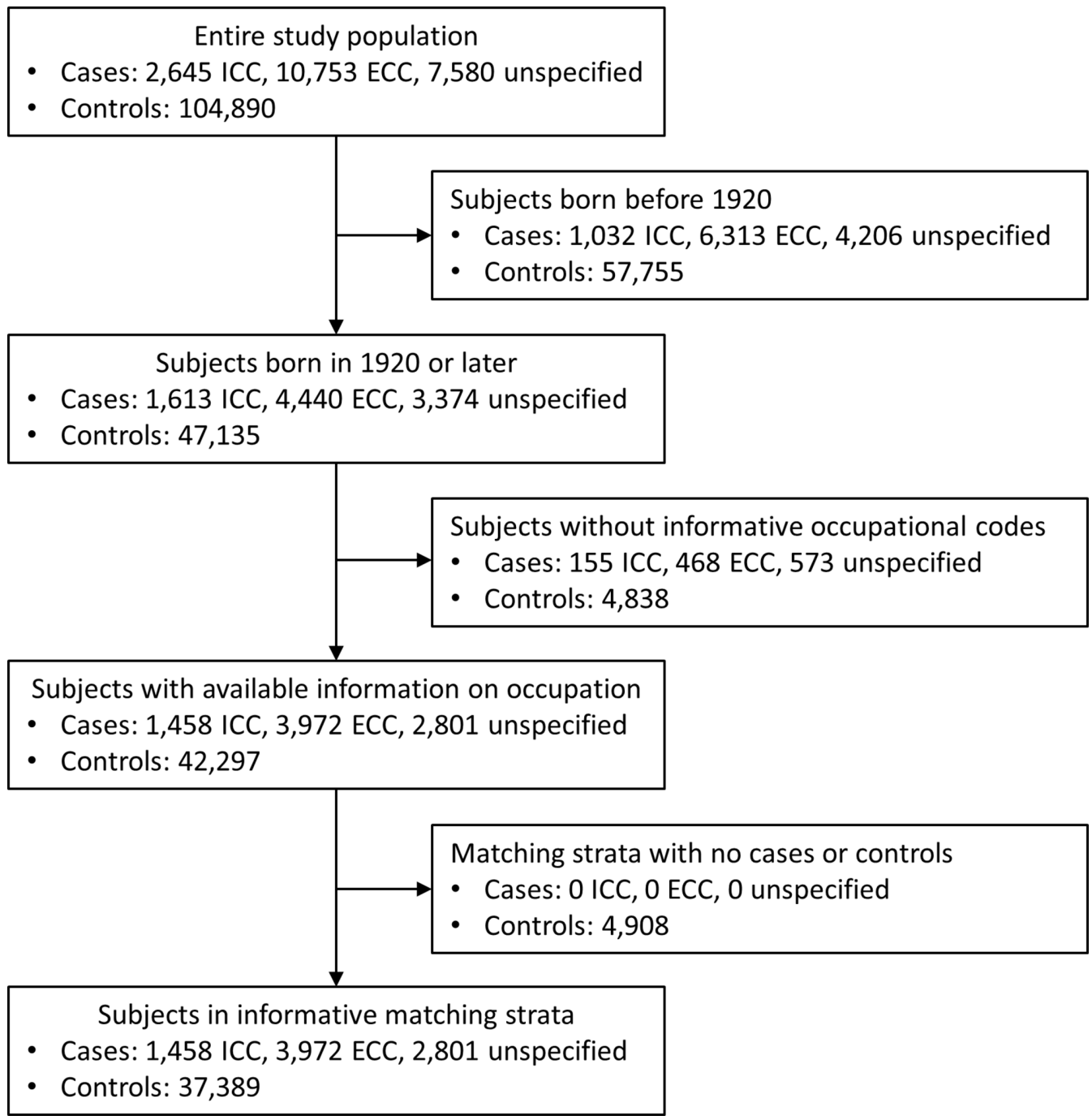

Figure 1 Flow diagram of the study population. 
Table 1 Characteristics of the study population

\begin{tabular}{|c|c|c|c|c|c|c|}
\hline & \multicolumn{2}{|c|}{ All cholangiocarcinoma* } & \multicolumn{2}{|c|}{ Intrahepatic cholangiocarcinoma* } & \multicolumn{2}{|c|}{ Extrahepatic cholangiocarcinoma* } \\
\hline & $\begin{array}{l}\text { Cases } \\
(\mathrm{n}=8231)\end{array}$ & $\begin{array}{l}\text { Controls } \\
(n=37389)\end{array}$ & $\begin{array}{l}\text { Cases } \\
(n=1458)\end{array}$ & $\begin{array}{l}\text { Controls } \\
(\mathrm{n}=6773)\end{array}$ & $\begin{array}{l}\text { Cases } \\
(\mathrm{n}=3972)\end{array}$ & $\begin{array}{l}\text { Controls } \\
(n=18221)\end{array}$ \\
\hline & n (\%) & $\mathrm{n}(\%)$ & n (\%) & n (\%) & $\mathrm{n}(\%)$ & $\mathrm{n}(\%)$ \\
\hline \multicolumn{7}{|l|}{ Gender } \\
\hline Female & $4317(52.5)$ & $18268(48.9)$ & $674(46.2)$ & $2937(43.4)$ & $1783(44.9)$ & $7523(41.3)$ \\
\hline Male & $3914(47.5)$ & $19121(51.1)$ & $784(53.8)$ & $3836(56.6)$ & $2189(55.1)$ & $10698(58.7)$ \\
\hline \multicolumn{7}{|l|}{ Birth cohort } \\
\hline 1920-1929 & $4416(53.7)$ & $19266(51.5)$ & $654(44.9)$ & $2929(43.3)$ & $2156(54.3)$ & $9553(52.4)$ \\
\hline 1930-1939 & $2322(28.2)$ & $10939(29.3)$ & $415(28.5)$ & $1971(29.1)$ & $1116(28.1)$ & $5288(29.0)$ \\
\hline 1940-1949 & $1177(14.3)$ & $5665(15.1)$ & $296(20.3)$ & $1426(21.0)$ & $549(13.8)$ & $2651(14.6)$ \\
\hline 1950-1960 & $316(3.8)$ & $1519(4.1)$ & $93(6.4)$ & $447(6.6)$ & $151(3.8)$ & $729(4.0)$ \\
\hline \multicolumn{7}{|l|}{ Reference aget } \\
\hline$\leq 59$ & $2736(33.2)$ & $12800(34.2)$ & $538(36.9)$ & $2542(37.5)$ & $1412(35.5)$ & $6604(36.2)$ \\
\hline $60-69$ & $3003(36.5)$ & $13593(36.4)$ & $502(34.4)$ & $2320(34.3)$ & 1416 (35.7) & $6507(35.7)$ \\
\hline$\geq 70$ & $2492(30.3)$ & $10996(29.4)$ & $418(28.7)$ & $1911(28.2)$ & $1144(28.8)$ & $5110(28.0)$ \\
\hline \multicolumn{7}{|c|}{ Reference period¥ } \\
\hline 1961-1970 & $21(0.3)$ & $94(0.3)$ & $0(0.0)$ & $0(0.0)$ & $17(0.4)$ & $77(0.4)$ \\
\hline 1971-1980 & $451(5.5)$ & $1959(5.2)$ & $46(3.2)$ & $194(2.9)$ & $256(6.5)$ & $1141(6.3)$ \\
\hline 1981-1990 & $1796(21.8)$ & $8012(21.4)$ & $266(18.2)$ & $1208(17.8)$ & 979 (24.6) & $4408(24.2)$ \\
\hline 1991-2005 & $5963(72.4)$ & $27324(73.1)$ & $1146(78.6)$ & $5371(79.3)$ & $2720(68.5)$ & $12595(69.1)$ \\
\hline \multicolumn{7}{|l|}{ Country } \\
\hline Finland & $3395(41.2)$ & $15306(40.9)$ & $549(37.7)$ & $2571(38.0)$ & $1353(34.1)$ & $6214(34.1)$ \\
\hline Iceland & $73(0.9)$ & $305(0.8)$ & $11(0.7)$ & $48(0.7)$ & $43(1.1)$ & $186(1.0)$ \\
\hline Norway & $1349(16.4)$ & $5870(15.7)$ & $260(17.8)$ & $1153(17.0)$ & $610(15.4)$ & $2699(14.8)$ \\
\hline Sweden & $3414(41.5)$ & $15908(42.6)$ & $638(43.8)$ & $3001(44.3)$ & 1966 (49.5) & $9122(50.1)$ \\
\hline \multicolumn{7}{|c|}{ Ever worked in the printing industry } \\
\hline No & $8138(98.9)$ & $36979(98.9)$ & $1426(97.8)$ & $6703(99.0)$ & $3933(99.0)$ & $18002(98.8)$ \\
\hline Yes & $93(1.1)$ & $410(1.1)$ & $32(2.2)$ & $70(1.0)$ & $39(1.0)$ & $219(1.2)$ \\
\hline \multicolumn{7}{|c|}{ Occupational exposure to asbestos } \\
\hline No & $6861(83.4)$ & $31052(83.0)$ & $1171(80.3)$ & $5548(81.9)$ & $3225(81.2)$ & $14727(80.8)$ \\
\hline Yes & $1370(16.6)$ & $6337(17.0)$ & $287(19.7)$ & $1225(18.1)$ & 747 (18.8) & $3494(19.2)$ \\
\hline
\end{tabular}

*2801 cases (1860 women and 941 men) were classified as cholangiocarcinoma but the coding scheme did not allow the distinction between intra- and extrahepatic cholangiocarcinoma. These cases are included in the 'All cholangiocarcinoma' column.

tReference age defined as age at diagnosis for cases and age at sampling for controls.

‡Reference period defined as period of diagnosis for cases and period of sampling for controls.

exposed to asbestos, the cumulative exposure index was highly correlated to the maximum intensity of exposure (Spearman's rho 0.97 ) and moderately correlated to the duration of exposure (Spearman's rho 0.54), while intensity and duration of exposure were only weakly correlated (Spearman's rho 0.39).

Table 2 and table D in online supplementary file show the association between the selected metrics for asbestos exposure and the risk of CC, ICC and ECC. Adjustment by work in the printing industry did not substantially change the estimates of interest. There were no associations between exposure to asbestos and the risk of ECC. However, for ICC, all metrics of exposure to asbestos were associated with the outcome. For maximum intensity and cumulative exposure, we observed a linear exposure-response relationship that was clearer for the cumulative exposure variable stratified into equally spaced intervals. The OR for subjects with a cumulative exposure of $\geq 15.0 \mathrm{f} /$ $\mathrm{mL} \times$ years compared with never exposed was 1.7 (95\% CI 1.1 to 2.6 ), suggesting a moderate/strong association. There was no statistically significant trend in risk according to duration of exposure to asbestos: all categories of duration showed an OR of 1.2 compared with never exposed.

Table 3 shows the effect of lagging the cumulative exposure when studying ICC. According to the BIC, the four models (unlagged, 10-, 20- or 30-year lag) did not differ substantially from each other (BIC ranged between 5036.3 and 5040.3). The BIC was lowest with a 20-year lag; in this analysis, the OR for subjects of the highest category of exposure $(\geq 15.0 \mathrm{f} / \mathrm{mL} \times$ years) compared with never exposed was 2.1 (95\% CI 1.2 to 3.7).

Table E in online supplementary file shows the OR for the association between the cumulative exposure to asbestos and ICC estimated in the analyses stratified by gender, country and reference age. As expected, the overall estimates were driven by the data observed among men, as very few women had exposure levels above $1.1 \mathrm{f} / \mathrm{mL} \times$ years. Associations were observed in all countries and the highest ORs were always observed for exposure levels $\geq 15 \mathrm{f} / \mathrm{mL} \times$ year, although the estimates were highly imprecise due to relatively small numbers. For the analysis stratified by reference age, there were fluctuations in the OR with broad confidence intervals, which hampered a clear interpretation of the risk estimates.

\section{DISCUSSION}

In this study there was an increased risk of ICC among subjects with a past occupational exposure to asbestos. We did not observe an association between occupational exposure to asbestos and ECC. 


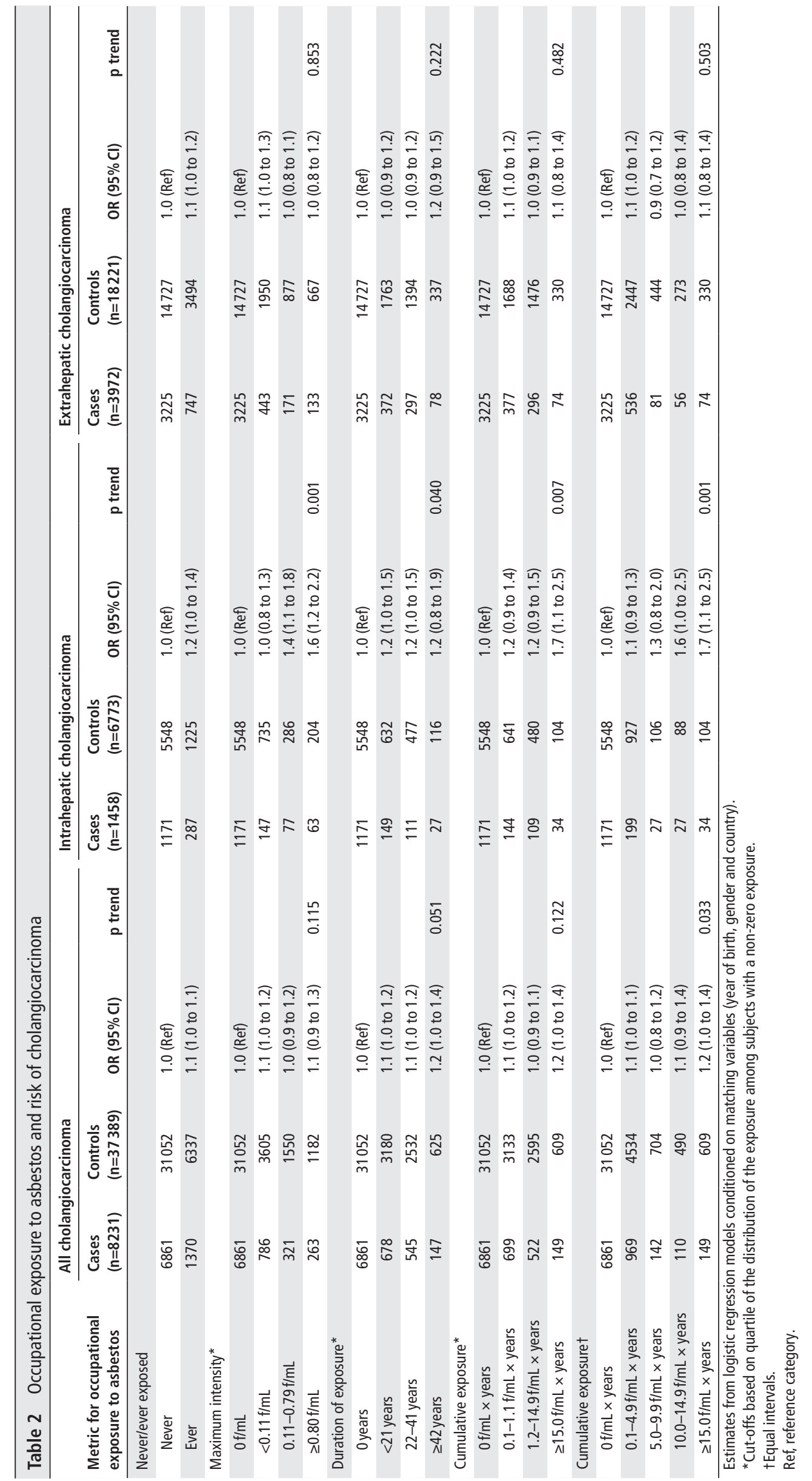


Table 3 Cumulative exposure to asbestos and risk of intrahepatic cholangiocarcinoma: comparison of unlagged/lagged exposure metrics

\begin{tabular}{|c|c|c|c|c|c|}
\hline Lag period & $\begin{array}{l}\text { Cases } \\
(\mathrm{n}=1458)\end{array}$ & $\begin{array}{l}\text { Controls } \\
(n=6773)\end{array}$ & OR $(95 \% \mathrm{Cl})$ & $\mathrm{p}$ trend & BIC \\
\hline No lag & & & & 0.004 & 5036.3 \\
\hline $0 \mathrm{f} / \mathrm{mL} \times$ years & 1171 & 5548 & 1.0 (Ref) & & \\
\hline $0.1-1.1 \mathrm{f} / \mathrm{mL} \times$ years & 144 & 641 & 1.2 (1.0 to 1.4$)$ & & \\
\hline $1.2-14.9 \mathrm{f} / \mathrm{mL} \times$ years & 109 & 480 & $1.2(1.0$ to 1.5$)$ & & \\
\hline$\geq 15.0 \mathrm{f} / \mathrm{mL} \times$ years & 34 & 104 & $1.7(1.1$ to 2.6$)$ & & \\
\hline 10-year lag & & & & 0.006 & 5037.6 \\
\hline $0 \mathrm{f} / \mathrm{mL} \times$ years & 1177 & 5564 & 1.0 (Ref) & & \\
\hline $0.1-1.1 \mathrm{f} / \mathrm{mL} \times$ years & 143 & 641 & $1.2(0.9$ to 1.4$)$ & & \\
\hline $1.2-14.9 \mathrm{f} / \mathrm{mL} \times$ years & 108 & 474 & $1.2(1.0$ to 1.5$)$ & & \\
\hline$\geq 15.0 \mathrm{f} / \mathrm{mL} \times$ years & 30 & 94 & 1.7 (1.1 to 2.6$)$ & & \\
\hline 20-year lag & & & & 0.003 & 5035.4 \\
\hline $0 \mathrm{f} / \mathrm{mL} \times$ years & 1196 & 5663 & 1.0 (Ref) & & \\
\hline $0.1-1.1 \mathrm{f} / \mathrm{mL} \times$ years & 133 & 586 & $1.2(1.0$ to 1.5$)$ & & \\
\hline $1.2-14.9 \mathrm{f} / \mathrm{mL} \times$ years & 110 & 477 & $1.2(1.0$ to 1.5$)$ & & \\
\hline$\geq 15.0 \mathrm{f} / \mathrm{mL} \times$ years & 19 & 47 & 2.1 (1.2 to 3.7$)$ & & \\
\hline 30-year lag & & & & 0.023 & 5040.3 \\
\hline $0 \mathrm{f} / \mathrm{mL} \times$ years & 1259 & 5923 & 1.00 (Ref) & & \\
\hline $0.1-1.1 \mathrm{f} / \mathrm{mL} \times$ years & 102 & 454 & $1.2(0.9$ to 1.5$)$ & & \\
\hline $1.2-14.9 \mathrm{f} / \mathrm{mL} \times$ years & 94 & 389 & $1.3(1.0$ to 1.6$)$ & & \\
\hline$\geq 15.0 \mathrm{f} / \mathrm{mL} \times$ years & 3 & 7 & 2.3 (0.6 to 8.8$)$ & & \\
\hline
\end{tabular}

Estimates from logistic regression models conditioned on matching variables (year of birth, gender and country).

BIC, Bayesian information criterion; Ref, reference category.

We observed an increased risk of ICC with all four asbestos exposure metrics (ever/never, intensity, duration and cumulative). Regarding quantitative asbestos metrics, clear signs of an exposure-response relationship were observed for intensity and cumulative exposure-two metrics that were highly correlated in our study population-but not for duration of exposure. Duration of exposure is a major determinant for most asbestos-related cancers (eg, lung cancer ${ }^{19}$ ). When interpreting our findings, we must consider that the duration of exposure was measured based on imputed data (all subjects were assumed to have worked between the age of 20 and 65 years and the midpoint between two censuses was used as a cut-off in the presence of exposure changes); hence, our risk estimates on the effect of the duration and the cumulative exposure should be interpreted with caution. The fact that, in all the four countries studied, the higher risk estimates were observed for highest category exposure provides further support for the presence of a causal association between asbestos exposure and ICC.

These findings are broadly in line with those from a previous case-control study carried out in Italy, where the association between asbestos exposure and ICC was stronger (ever vs never exposed, OR 4.8, 95\% CI 1.7 to 13.3) than for ECC (OR 2.1, 95\% CI 0.8 to 5.3$).{ }^{11}$ However, the relative risks estimated in the Italian study were much higher than those observed in the Nordic countries. Several factors could contribute to the observed differences. The estimates from Brandi et al were based on a small number of cases and risk estimates were imprecise. ${ }^{11}$ Moreover, these estimates might have been affected by referral bias, as a group of cases enrolled at a tertiary centre for the diagnosis and treatment of CC were compared with a historical control group, including inpatients and outpatients recruited to study the occupational aetiology of three conditions (carpal tunnel syndrome, renal carcinoma and retinal detachment). ${ }^{20-22}$ A sensitivity analysis restricted to cases and controls from the district where the hospital is located produced slightly lower risk estimates, particularly for ECC (ICC: OR 3.4, 95\% CI 1.0 to 11.5; ECC: OR 1.4, 95\% CI 0.4 to 4.7$).{ }^{11}$ Morever, the risk estimates derived from the NOCCA data might be biased towards null due to the limited amount of information on occupation, which could lead to non-differential misclassification of the exposure variable. Also, the use of asbestos in Italy was more intense and prolonged than in the Nordic countries. ${ }^{23}$ Therefore, it is possible that the average cumulative exposure among ever exposed subjects in the Italian study (which was the only metric reported in the study) might be higher than that of ever exposed workers in the present Nordic study population.

To our knowledge, the present Nordic study and the Italian one are the only studies that have specifically addressed the risk of CC associated with asbestos exposure. An increased risk of liver cancer among workers exposed to asbestos has been reported in some occupational cohorts, but these studies grouped together all liver cancers, sometimes also adding all bile duct neoplasms. ${ }^{2425}$

The presence of asbestos fibres in liver tissue was first reported more than three decades ago. ${ }^{26} 27$ In addition, a recent study from the region of Casale Monferrato, Italy, known for its high incidence of asbestos-related cancers, demonstrated the presence of asbestos fibres in gallbladder removed to treat cholelithiasis several years after the Italian ban of asbestos. ${ }^{28}$ How asbestos fibres can reach the liver tissue is still unclear. Miserocchi and colleagues hypothesised that the fibres, drained by the pulmonary lymphatic system, could reach the blood and then potentially translocate to all organs. ${ }^{29}$ Once in the liver, asbestos fibres might produce a chronic inflammatory status and lead to impaired cell proliferation and apoptosis. ${ }^{30}$ The anatomical features of the bile ducts could explain the differences observed between ICC and ECC; asbestos fibres might be more likely to remain trapped in the smaller bile ducts. Moreover, current knowledge supports the hypothesis that different pluripotent 
stem cells could be involved in the carcinogenic process of ICC and ECC. ${ }^{4}$

\section{Study strengths and limitations}

The main strengths of our study are the large population base and the high number of cases analysed. Also, thanks to the use of standard diagnostic codes, we were able to distinguish the site of occurrence (extra- or intrahepatic) for most cases $(63.5 \%)$, enabling us to present separate estimates for ICC and ECC. Finally, the occupational exposure to asbestos was quantified based on a job-exposure matrix that was created without any knowledge of the aetiological hypothesis under investigation in the present study. ${ }^{15}$

The main limitation of the present register-based study is the absence of information on potential confounders other than work-related ones, such as liver diseases and personal habits. In the Nordic countries, some of the established risk factors for CC might be more common among subjects from lower socioeconomic classes (eg, alcohol-related liver cirrhosis ${ }^{31}$ ) and might be associated with a history of asbestos exposure. Increased mortality for liver diseases has been documented in the Nordic countries in some groups of workers performing occupations with potential exposure to asbestos (eg, miners and quarry workers, construction workers, plumbers and painters). ${ }^{12}$ However, we observed very different risk estimates for ICC and ECC; hence, the confounding pattern should differ substantially between the two forms and be strong enough to largely inflate the OR for ICC (the OR for exposure levels $\geq 15 \mathrm{f} / \mathrm{mL} \times$ years was as high as 2.1 when a 20 -year lag was allowed). This seems unlikely as alcohol-related liver diseases such as liver cirrhosis are considered to be risk factors for both ICC and ECC (although the magnitude of the risks is probably higher for ICC). ${ }^{7}$ For these reasons, we do not believe that the absence of information on established risk factors for CC might fully explain the pattern or risk estimates that we have observed for ICC; however, we cannot exclude a minor overestimation of the OR due to a possible different distribution of chronic liver diseases by occupation. A second limitation is the potential for exposure misclassification, as the exposure assessment was performed based on job titles (no direct asbestos measurement information available at the individual level). A recent analysis of the Swedish component of the NOCCA study showed an increased risk of mesothelioma in occupations not considered, according to the NOCCA JEM, exposed to asbestos or other chemical carcinogens. ${ }^{32}$ Among women, the occupations of canning workers and clearers showed an increased risk of mesothelioma not predicted by the NOCCA JEM. ${ }^{32}$ This observation suggests that the use of the NOCCA JEM fails to capture the risk of asbestos-related mesothelioma occurring in occupations where the proportion of workers exposed to asbestos is low $(<5 \%)$. $^{32}$ In our specific case, also considering the high proportion of CC cases recorded among women, it is possible that a certain proportion of workers classified as 'unexposed' had actually been exposed to asbestos; this fact is likely to have biased our estimates towards the null hypothesis. However, our most notable finding is the raised risk of ICC observed among men with high levels of exposure to asbestos. In this subpopulation, the bias due to sources of exposure not captured by the JEM should be minimal. We did not have access to the entire working history of the enrolled subjects, and thus we had to assume similar exposures to asbestos between censuses, which is imprecise. Moreover, the starting and ending employment dates were not available and we assumed that all subjects worked between the ages of 20 and 65 years. Also, some of the workers included in the present analysis might have been exposed to asbestos a few years before 1945 (we included all people born in 1920 or later); thus, the length of exposure to asbestos might have been underestimated for a small proportion of our study population. There is no reason to suspect that the exposure misclassification might be differential with respect to the case/control status; hence, this potential source of bias is more likely to have attenuated rather than inflated our risk estimates. In our analysis we could only evaluate the association between CC and occupational exposure to asbestos, while we had no information on other non-occupational sources of exposure to asbestos. $^{33}$ Also, the NOCCA JEM is based on data referring to airborne concentration of asbestos fibres at the working places ${ }^{15}$; hence, the JEM implicitly assumes that the main route of exposure is inhalation. However, in the case of CC, enteric absorption of ingested asbestos fibres-possibly due to non-occupational sources of exposure such as the consumption of contaminated drinking water-might play a role. ${ }^{34}$ Also, due to the limited knowledge available on the carcinogenic process linking asbestos exposure to ICC, we cannot exclude the possibility that exposures occurring early in life might be important determinants of the disease. An experimental study demonstrated that, in mice, ingested asbestos fibres can cross the placenta and accumulate in the liver of the fetus. ${ }^{35}$ This finding is in line with those from an epidemiological study that documented the presence of asbestos fibres in the liver of stillborn infants from mothers without a known occupational exposure to asbestos. ${ }^{36}$ Due to the lack of information on established personal risk factors, we could not explore the role of asbestos in the initiation and/or promotion of CC. Hence, our study does not provide information on the role of asbestos as a co-carcinogen acting only in the presence of an already initiated carcinogenic process. A final limitation of our study is the relatively low level of exposure to asbestos observed among both cases and controls. Asbestos use was banned in Iceland, Sweden and Norway during the early 1980s, but in Finland its use continued until 1993. Therefore, even the highest asbestos exposure categories in this study are not especially high compared with the highest exposure levels worldwide.

\section{CONCLUSIONS}

This is the first large population-based study which supports the hypothesis that occupational exposure to asbestos is a risk factor for ICC, but not for ECC. Further studies designed to carefully assess the asbestos exposure history and to account for potential confounders are necessary to establish the causality of the observed association and to define with precision the magnitude of the risk.

\section{Author affiliations}

'Department of Medical and Surgical Sciences (DIMEC), University of Bologna, Bologna, Italy

International Agency for Research on Cancer, Lyon, France

${ }^{3}$ Department of Experimental, Diagnostic, and Specialty Medicine, S. Orsola-Malpighi University Hospital, Bologna, Italy

${ }^{4}$ G.Prodi' Interdepartmental Center for Cancer Research, University of Bologna, Bologna, Italy

${ }^{5}$ Department of Research, Cancer Registry of Norway, Institute of Population-Based Cancer Research, Oslo, Norway

${ }^{6}$ Department of Medical Epidemiology and Biostatistics, Karolinska Institutet, Stockholm, Sweden

${ }^{7}$ Icelandic Cancer Registry, Reykjavik, Iceland

${ }^{8}$ Faculty of Medicine, University of Iceland, Reykjavik, Iceland

${ }^{9}$ Department of Community Medicine, Faculty of Health Sciences, University of Tromsø, The Arctic University of Norway, Tromsø, Norway

${ }^{10}$ Genetic Epidemiology Group, Folkhälsan Research Center, Helsinki, Finland

${ }^{11}$ Faculty of Social Sciences, University of Tampere, Tampere, Finland 
${ }^{12}$ Finnish Cancer Registry, Institute for Statistical and Epidemiological Cancer Research, Helsinki, Finland

Contributors $E P, K S$ and SM contributed to the conception of the study. AF, EP, FSV, $\mathrm{GBi}, \mathrm{GBr}, \mathrm{JIM}, \mathrm{KS}, \mathrm{SC}$ and SM contributed to the design of the study. EP, EW, JIM, KK, LT and PS contributed to the collection of data. AF, JIM, SC and SM contributed to the analysis of data. AF, EP, FSV, GBr, KS, SC and SM contributed to the interpretation of data. AF, FSV, GBr, SC and SM contributed to drafting the article. EP, EW, GBi, JIM, $\mathrm{KK}, \mathrm{KS}, \mathrm{LT}$ and PS contributed to the critical revision of the article. All authors read and approved the final version of the manuscript.

Funding Nordic Cancer Union funded the NOCCA project. The work by AF, GBr, SC, GBi, FSV and SM was partially supported by internal funds of the Department of Medical and Surgical Sciences and the Department of Experimental, Diagnostic, and Specialty Medicine of the University of Bologna.

Competing interests None declared.

Ethics approval The NOCCA study has been approved by the ethical committees and the data inspection boards in each of the Nordic countries.

Provenance and peer review Not commissioned; externally peer reviewed.

Open Access This is an Open Access article distributed in accordance with the Creative Commons Attribution Non Commercial (CC BY-NC 4.0) license, which permits others to distribute, remix, adapt, build upon this work non-commercially, and license their derivative works on different terms, provided the original work is properly cited and the use is non-commercial. See: http://creativecommons.org/ licenses/by-nc/4.0/

(c) Article author(s) (or their employer(s) unless otherwise stated in the text of the article) 2018. All rights reserved. No commercial use is permitted unless otherwise expressly granted.

\section{REFERENCES}

1 Patel T. Cholangiocarcinoma controversies and challenges. Nat Rev Gastroenterol Hepatol 2011;8:189-200.

2 Patel T. Cholangiocarcinoma controversies and challenges. Nat Clin Pract Gastroenterol Hepatol 2006;3:33-42.

3 Nault JC, Zucman-Rossi J. Genetics of hepatobiliary carcinogenesis. Semin Liver Dis 2011;31:173-87.

4 Cardinale V, Semeraro R, Torrice A, et al. Intra-hepatic and extra-hepatic cholangiocarcinoma: new insight into epidemiology and risk factors. World $\mathrm{J}$ Gastrointest Oncol 2010:2:407-16.

5 Bergquist A, von Seth E. Epidemiology of cholangiocarcinoma. Best Pract Res Clin Gastroenterol 2015:29:221-32.

6 Patel T. New insights into the molecular pathogenesis of intrahepatic cholangiocarcinoma. J Gastroenterol 2014:49:165-72.

7 Farioli A, Brandi G. Risk factors of cholangiocarcinoma. In: Brandi G, Ercolani G, eds Cholangiocarcinoma. New York: Nova Science Publishers, 2015.

8 Kumagai S, Kurumatani N, Arimoto A, et al. Cholangiocarcinoma among offset colour proof-printing workers exposed to 1,2-dichloropropane and/or dichloromethane. Occup Environ Med 2013;70:508-10.

9 Kumagai S, Sobue T, Makiuchi T, et al. Relationship between cumulative exposure to 1,2-dichloropropane and incidence risk of cholangiocarcinoma among offset printing workers. Occup Environ Med 2016;73:545-52.

10 Vlaanderen J, Straif K, Martinsen Jl, et al. Cholangiocarcinoma among workers in the printing industry: using the NOCCA database to elucidate the generalisability of a cluster report from Japan. Occup Environ Med 2013;70:828-30.

11 Brandi G, Di Girolamo S, Farioli A, et al. Asbestos: a hidden player behind the cholangiocarcinoma increase? Findings from a case-control analysis. Cancer Causes Control 2013:24:911-8.
12 Pukkala E, Martinsen Jl, Lynge E, et al. Occupation and cancer: follow-up of 15 million people in five Nordic countries. Acta Oncol 2009;48:646-790.

13 Hillerdal G. The Swedish experience with asbestos: history of use, diseases, legislation, and compensation. Int J Occup Environ Health 2004;10:154-8.

14 Ulvestad B, Kjaerheim K, Møller B, et al. Incidence trends of mesothelioma in Norway, 1965-1999. Int J Cancer 2003:107:94-8.

15 Kauppinen T, Heikkilä P, Plato N, et al. Construction of job-exposure matrices for the Nordic Occupational Cancer Study (NOCCA). Acta Oncol 2009:48:791-800.

16 Kauppinen T, Toikkanen J, Pukkala E. From cross-tabulations to multipurpose exposure information systems: a new job-exposure matrix. Am J Ind Med 1998:33:409-17.

17 Kauppinen T, Uuksulainen S, Saalo A, et al. Trends of occupational exposure to chemical agents in Finland in 1950-2020. Ann Occup Hyg 2013;57:593-609.

18 Schwarz G. Estimating the dimension of a model. Annals of Statistics 1978;6:461-4.

19 Pira E, Romano C, Violante FS, et al. Updated mortality study of a cohort of asbestos textile workers. Cancer Med 2016:5:2623-8.

20 Mattioli S, Baldasseroni A, Bovenzi M, et al. Risk factors for operated carpal tunnel syndrome: a multicenter population-based case-control study. BMC Public Health 2009:9:343.

21 Mattioli S, Truffelli D, Baldasseroni A, et al. Occupational risk factors for renal cell cancer: a case-control study in northern Italy. J Occup Environ Med 2002:44:1028-36.

22 Mattioli S, De Fazio R, Buiatti E, et al. Physical exertion (lifting) and retinal detachment among people with myopia. Epidemiology 2008;19:868-71.

23 Marinaccio A, Binazzi A, Di Marzio D, et al. Incidence of extrapleural malignant mesothelioma and asbestos exposure, from the Italian national register. Occup Environ Med 2010;67:760-5.

24 Boulanger $\mathrm{M}$, Morlais $\mathrm{F}$, Bouvier $\mathrm{V}$, et al. Digestive cancers and occupational asbestos exposure: incidence study in a cohort of asbestos plant workers. Occup Environ Med 2015;72:792-7.

25 Wu WT, Lin YJ, Li CY, et al. Cancer attributable to asbestos exposure in shipbreaking workers: a matched-cohort study. PLoS One 2015;10:e0133128.

26 Auerbach 0, Conston AS, Garfinkel L, et al. Presence of asbestos bodies in organs other than the lung. Chest 1980:77:133-7.

27 Szendröi M, Németh L, Vajta G. Asbestos bodies in a bile duct cancer after occupational exposure. Environ Res 1983;30:270-80.

28 Grosso F, Randi L, Croce A, et al. Asbestos fibers in the gallbladder of patients affected by benign biliary tract diseases. Eur J Gastroenterol Hepatol 2015;27:860-4.

29 Miserocchi G, Sancini G, Mantegazza F, et al. Translocation pathways for inhaled asbestos fibers. Environ Health 2008;7:4.

30 Manning CB, Vallyathan V, Mossman BT. Diseases caused by asbestos: mechanisms of injury and disease development. Int Immunopharmacol 2002;2:191-200.

31 Mackenbach JP, Kulhánová I, Bopp M, et al. Inequalities in alcohol-related mortality in 17 European countries: a retrospective analysis of mortality registers. PLoS Med 2015;12:e1001909

32 Plato N, Martinsen JI, Sparén P, et al. Occupation and mesothelioma in Sweden: updated incidence in men and women in the 27 years after the asbestos ban. Epidemiol Health 2016:38:e2016039.

33 Goldberg M, Luce $\mathrm{D}$. The health impact of nonoccupational exposure to asbestos: what do we know? Eur J Cancer Prev 2009;18:489-503.

34 Di Ciaula A. Asbestos ingestion and gastrointestinal cancer: a possible underestimated hazard. Expert Rev Gastroenterol Hepatol 2017;11:419-25.

35 Haque AK, Ali I, Vrazel DM, et al. Chrysotile asbestos fibers detected in the newborn pups following gavage feeding of pregnant mice. J Toxicol Environ Health $A$ 2001;62:23-31.

36 Haque AK, Vrazel DM, Uchida T. Assessment of asbestos burden in the placenta and tissue digests of stillborn infants in South Texas. Arch Environ Contam Toxicol 1998:35:532-8. 